\title{
Patterns and trends of high-impact weather in China during 1959-2014
}

\author{
Jun Shi ${ }^{1,2}$, Kangmin Wen ${ }^{1,2}$, and Linli Cui ${ }^{3}$ \\ ${ }^{1}$ Shanghai Climate Center, Shanghai Meteorological Bureau, Shanghai 200030, China \\ ${ }^{2}$ Ecological Technique and Engineering College, Shanghai Institute of Technology, Shanghai 201418, China \\ ${ }^{3}$ Shanghai Center for Satellite Remote Sensing and Application, Shanghai 201199, China
}

Correspondence to: Jun Shi (shij@climate.sh.cn)

Received: 7 September 2015 - Published in Nat. Hazards Earth Syst. Sci. Discuss.: 9 October 2015

Revised: 8 March 2016 - Accepted: 9 March 2016 - Published: 23 March 2016

\begin{abstract}
The spatial and temporal characteristics of the frequencies of four types of high-impact weather (HIW), i.e. snowfall, thunderstorms, fog and hailstorms, were analysed in China during 1959-2014. Results indicate a significant decrease in the number of snowfall days, thunderstorm days and thunderstorm spells in all six regions of China, with regional decreasing rates of 0.1-3.4 days, 1.65.1 days and $0.23-0.77$ times per decade respectively. The number of foggy days, hailstorm days and snowfall spells decreased at rates of $0.2-1.8$ days, $0.1-0.7$ days and 0.14 0.44 times per decade respectively in almost all regions and fog and hailstorm spells decreased at rates of 0.06-0.17 and 0.001-0.043 times per decade respectively in most regions of China. Spatially, there was more snowfall in northeastern China and western China, and more thunderstorms in southern China and southwestern China. The number of fog events was larger in some high mountain stations, eastern China and central China. Hailstorms were concentrated on QinghaiTibet Plateau. Over the past 56 years, snowfall days, thunderstorm days and thunderstorm spells decreased in most parts of China, and hailstorm days decreased in northeastern China, most parts of northern China and Tibet, southern Qinghai and western Sichuan. The spatial trends of foggy days, foggy spells, snowfall spells and hailstorm spells were not significant in most parts of China. With global warming, some types of HIW are likely to increase in their intensities, so more mitigation and adaptation strategies are still essential for local government and the public in China.
\end{abstract}

\section{Introduction}

The globally averaged surface temperature data, as calculated by a linear trend, show a warming of 0.85 [0.65 to $1.06]^{\circ} \mathrm{C}$ over the period 1880 to 2012 , and the increase of global surface temperatures for 2081-2100 relative to 19862005 is projected to likely be in the range of $0.3-4.8^{\circ} \mathrm{C}$ (IPCC, 2013). High-impact weather (HIW) is weather that can result in significant impacts on safety, property and/or socioeconomic activity (Sills, 2009). Storm, typhoon, snowfall, fog and haze can often lead to flood, flash flood, debris flow and low visibility, and cause significant economic, social and environmental impacts and damage; thus, this kind of weather is called HIW (Li et al., 2013; Done et al., 2015; Shi et al., 2015). During 2001-2010, our world suffered unparalleled high-impact climate extremes in history, and over 370000 people died from extreme weather and climate events (WMO, 2013). Analysis of the long-term climatic characteristics of HIW is conducive to improving the weather forecast capacity, reducing the loss of human life and property and developing climate change mitigation and adaptation plans (de Vyver, 2012; Li et al., 2013), which further has great significance for national economic and social development.

China, a region with complex topography and strongly influenced by Asian monsoon circulation, is especially vulnerable to frequent weather and climate disasters (Jiang et al., 2012). The main HIW in China includes typhoons, rainstorms, thunderstorms, gales, heatwaves, fog, haze, hailstorms, tornadoes and snowstorms (Shi and Cui, 2012). Previous studies have investigated the variations of some types 
of HIW in China; for example, Yu et al. (2012) analysed the frequency variation of thunderstorms, hailstorms and gales in eastern China from 1971 to 2000. Fu et al. (2013) examined the variability in the frequency of extreme precipitation events in China during 1961-2009. Zhu et al. (2014) investigated the spatiotemporal variation patterns of snowfall days in Qinghai province from 1962 to 2012. Sun et al. (2014) quantified the causes of extreme summer heat of 2013 and projected its future likelihood in eastern China. Shi et al. (2015) analysed the evolution characteristics of eight types of HIW and their causes in the Yangtze River Delta during 1959-2010.

However, there are some insufficiencies in the previous studies. First of all, the study areas of some studies are only parts of China, so the results are incapable of reflecting the overall situation of HIW in China. Moreover, the findings from previous studies cannot reveal the latest dynamics of HIW owing to lack of up-to-date observational data. Meanwhile, the majority of existing studies are concerned with the frequency of HIW events based on monthly or annual data, and there is a lack of analysis of the continuity or spells of HIW using daily data. Finally, most of the former studies focus on temperature and/or precipitation extremes, and few studies consider other types of HIW, such as thunderstorms, fog, snowfall or hailstorms (Yu et al., 2012; Zhu et al., 2014; Shi et al., 2015). The evolution characteristics of the thunderstorms, fog, snowfall and hailstorms are actually essential to social activities and people's lives under the background of climate change.

The objectives of this study are to examine the distribution patterns and variation trends in the number of days and spells of four types of HIW, i.e. snowfall, thunderstorms, fog and hailstorms, based on the daily weather monitoring data of the whole China during 1959-2014. The outline of the paper is as follows. After describing the data set and the methodology in Sect. 2, the spatial and temporal characteristics of different types of HIW are analysed in Sect. 3. This is followed by a discussion of the main findings in Sect. 4, and finally, a summary of the main conclusions is provided in Sect. 5 .

\section{Data and method}

\subsection{Data}

The daily weather phenomenon data, provided by the National Meteorological Information Center, China Meteorological Administration (NMIC/CMA), were used to derive the days and spells of high-impact weather (HIW) in China. These data have 756 available stations and span from 1951 to 2014. We excluded those data before 1959 because there were not enough stations (Fu et al., 2013), and we also removed those stations with more than $10 \%$ missing values. Finally, 604 stations were selected for this study, with comparatively complete records of daily snowfall, thunderstorm, fog and hailstorm weather phenomena. Thunderstorms have ceased to be observed at Chinese weather stations since 2014, so the thunderstorm data actually span from 1959 to 2013. The administrative division of China and the spatial distribution of selected meteorological stations are shown in Fig.1.

The selected stations are maintained according to the criteria of WMO's Guide to the Global Observing System and CMA's Technical Regulations on Weather Observations. The missing values were filled in by weather phenomenon data of the neighbouring stations through a simple linear regression method or by the climatological standard normals, 19812010 of the station itself. For a given station with missing data, the surrounding observatories which have linear distances of less than $100 \mathrm{~km}$ and Pearson correlation significance $(P e)$ levels less than 0.01 are considered as reference series. Considering the local-scale extent of HIW and sparse meteorological stations, the missing values in Xinjiang, Tibet, Qinghai and Inner Mongolia were all filled in by the climatological standard normals, 1981-2010 of the station itself, and the interpolation results of HIW in western China may not be able to reflect the actual distribution and variation trend to some extent.

\subsection{Method}

\subsubsection{The definition of high-impact weather}

In this study, the definition of four types of HIW is in accordance with Standard of the Surface Observation about Meteorology (China Meteorological Administration, 2003) and Glossary of Meteorology (Glickman, 2000). Snowfall is the spell of precipitating snow in the form of flakes of crystalline water ice from clouds, and it tends to form within regions of updraft gas around extratropical cyclone. Thunderstorm is a type of storm in which there is thunder and lightning, and can develop in any geographic location, especially in midlatitude regions when warm and moist air collides with cooler air. Fog is a visible mass consisting of cloud water droplets or ice crystals at or near the Earth's surface, which reduces visibility to less than $1 \mathrm{~km}$. When the difference between air temperature and dew point is less than $2.5^{\circ} \mathrm{C}$, fog tends to form. Hail is a kind of solid precipitation consisting of balls or irregular lumps of ice, each of which is called a hailstone. Any thunderstorm which produces hail that reaches the ground is referred to as a hailstorm. If any of the above-mentioned weather phenomena occurred on 1 day simultaneously, the day was recorded as the corresponding type of HIW respectively.

\subsubsection{The sequence of high-impact weather days}

For each type of HIW, i.e. snowfall, thunderstorms, fog or hailstorms, the monthly number of days in each station was counted directly from the daily weather phenomenon data, and the annual number of days was the sum of monthly val- 

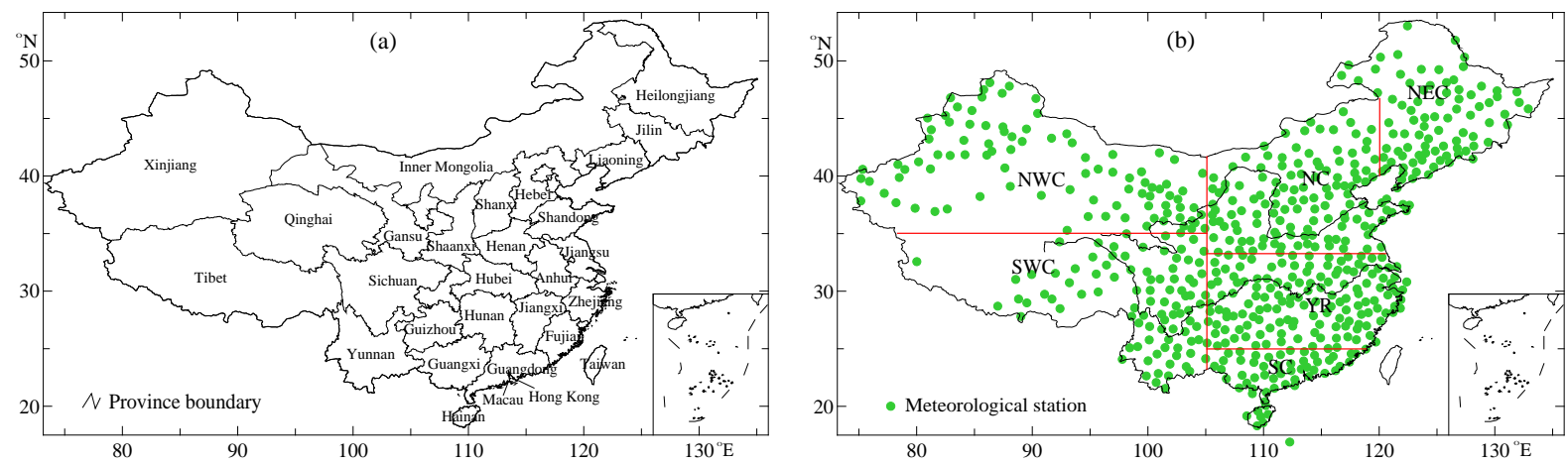

Figure 1. The administrative division (a) and spatial distribution of meteorological stations and regions of China (b). China is divided into six regions, namely, Northeast China (NEC), North China (NC), the mid-lower Yangtze River valley (YR), South China (SC), Northwest China (NWC) and Southwest China (SWC).

Table 1. Linear trends of annual average spells of high-impact weather in China during 1959-2014 (unit: times decade ${ }^{-1}$ ).

\begin{tabular}{lllllll}
\hline \multirow{2}{*}{ High-impact weather } & \multicolumn{7}{c}{ Regions of China } \\
\cline { 2 - 7 } & NEC & NC & YR & SC & NWC & SWC \\
\hline Snowfall spells & -0.396 & -0.304 & -0.135 & $-0.005^{*}$ & -0.259 & -0.436 \\
Thunderstorm spells & -0.285 & -0.360 & -0.584 & -0.768 & -0.232 & -0.675 \\
Foggy spells & -0.075 & $-0.009^{*}$ & -0.168 & -0.063 & $-0.005^{*}$ & -0.129 \\
Hailstorm spells & -0.001 & -0.002 & $-0.001^{*}$ & $-0.000^{*}$ & -0.008 & -0.043 \\
\hline
\end{tabular}

* Variations not statistically significant at the 0.05 level.

ues during that year. To obtain the sequence of annual average days of HIW events in each region of China, China was divided into six regions, i.e. Northeast China (NEC), North China (NC), the mid-lower Yangtze River valley (YR), South China (SC), Northwest China (NWC) and Southwest China (SWC) according to natural geography, climate and other published papers (Xu et al., 2011), as shown in Fig. 1b. Annual average days of HIW events were calculated using the station-averaged method according to the number of stations in each region of China.

\subsubsection{The sequence of high-impact weather spells}

According to the number of consecutive days, weather spells and long weather spells were further selected from the daily weather phenomenon data. A weather spell is defined as the same weather type which occurred on no less than 3 consecutive days, and a long weather spell is the same weather which occurred on no less than 7 consecutive days. Two types of weather spells were determined and the number of spells for each type of HIW was counted annually in each station. Similarly, the annual average number of spells for each type of HIW was calculated as arithmetic averages according to the number of stations in each region of China.

\subsubsection{Temporal characteristics of the frequencies of high-impact weather}

To find out the timing dynamics of HIW in each region of China, the distribution and trend of annual average days and annual average number of spells for each type of HIW was analysed respectively, and average annual number of days and spells for each type of HIW were also calculated and compared during five periods, i.e. 1959-1970, the 1970s (1971-1980), the 1980s (1981-1990), the 1990s (1991-2000) and 2001-2014. Based on the annual sequence of the days and spells of HIW in each region of China, the linear trend was calculated using the method of ordinary least squares regression (Kruger and Sekele, 2013; de Lima et al., 2013), and was tested for statistical significance at the 0.05 confidence level using a two-tailed $t$ test (Wang et al., 2013).

\subsubsection{Spatial characteristics of the frequencies of high-impact weather}

Based on the annual sequence of HIW in each station, the long-term average annual number of days and annual number of spells of each type of HIW was calculated respectively in each station, and the linear trend was also calculated using the method of ordinary least squares regression in each station. According to the longitude and latitude of each station, the spatial distribution and trend in the days and spells 

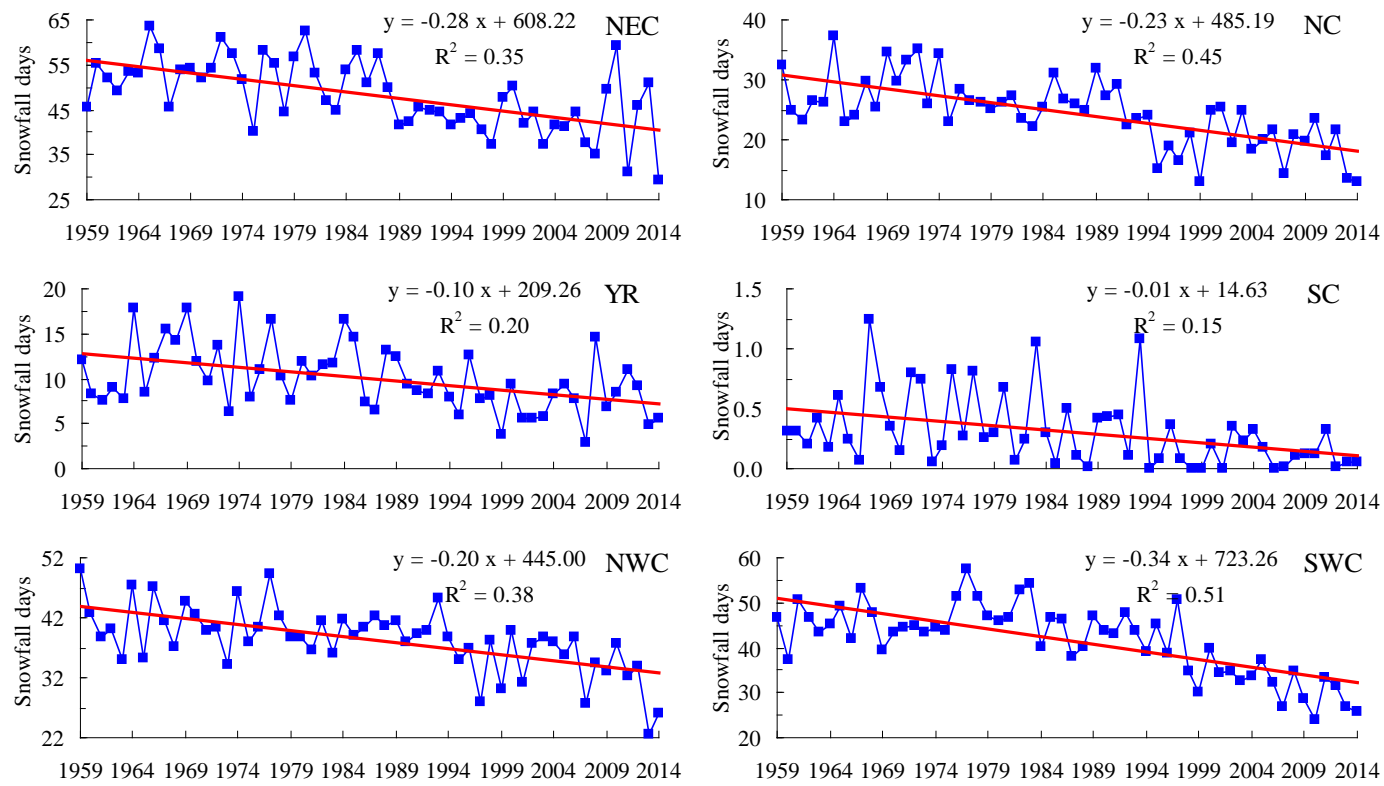

Figure 2. Variations of annual average snowfall days in six regions of China during 1959-2014. (The blue lines are the annual value and the red lines are the linear trend, the same as below.)

of HIW were established using the inverse distance weighted interpolation technique and were drawn with Surfer 8 (a professional drawing software). Regions with significant trends were highlighted and coloured, while those with insignificant trends were not coloured and shown as white spaces in the trend maps. The spatial distribution indicates the general pattern of HIW in China, and the spatial trend demonstrates the linear regression coefficient on a decade timescale.

\section{Results}

\subsection{Temporal characteristics of the days and spells of high-impact weather}

\subsubsection{Temporal variations in annual snowfall days and snowfall spells}

During 1959-2014, annual average days and spells of snowfall decreased in all six regions of China, especially in NEC, NC, YR, NWC and SWC, the decreasing trends in both days and spells of snowfall were all significant (Table 1 and Fig. 2). Snowfall decreased at rates of 2.8, 2.3, 1.0, 2.0 and 3.4 days per decade, and snowfall spells decreased at rates of $0.40,0.30,0.14,0.26$ and 0.44 times per decade in NEC, NC, YR, NWC and SWC respectively. In SC, snowfall decreased significantly at a rate of 0.1 days per decade, but the decreasing trend of snowfall spells was not significant. During 2001-2014, the number of days and spells of snowfall was the smallest in all six regions, and in the 1970s, it was the largest in NEC, NC, SC and SWC. The maximum days and spells of snowfall occurred at Tulogart station in
Xinjiang, which was 239 days in 1966 and 33 times in 1976 respectively.

\subsubsection{Temporal variations in annual thunderstorm days and thunderstorm spells}

Annual average days and spells of thunderstorms decreased significantly in all six regions of China during 1959-2013 (Table 1 and Fig. 3). Thunderstorms decreased at rates of 1.6, 2.1, 3.5, 5.1, 1.6 and 4.0 days per decade, and thunderstorm spells decreased at rates of $0.29,0.36,0.58,0.77,0.23$ and 0.68 times per decade in NEC, NC, YR, SC, NWC and SWC respectively. In six regions, both the days and the spells of thunderstorms have decreased continuously over the past 55 years. During 2001-2013, the number of days and spells of thunderstorms was the smallest in all six regions, and during 1959-1970, it was the largest in NEC, NC, YR, NWC and SWC. The maximum days and spells of thunderstorms occurred at Jinghong station in Yunnan, which was 149 days in 1964 and 25 times in 1968 respectively.

\subsubsection{Temporal variations in annual foggy days and foggy spells}

Annual average days and spells of foggy weather decreased in all six regions of China, especially in NEC, YR, SC and SWC, the decreasing trends in both days and spells of foggy weather were all significant (Table 1 and Fig. 4). During 1959-2014, foggy weather decreased at rates of 1.2, 1.8, 1.0 and 1.8 days per decade and foggy weather spells decreased at rates of $0.08,0.17,0.06$ and 0.13 times per decade in NEC, YR, SC and SWC respectively. In NC, the decreasing trends 


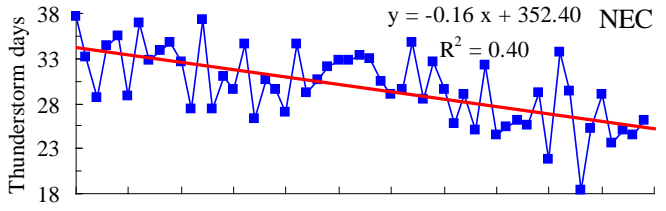

195919641969197419791984198919941999200420092014
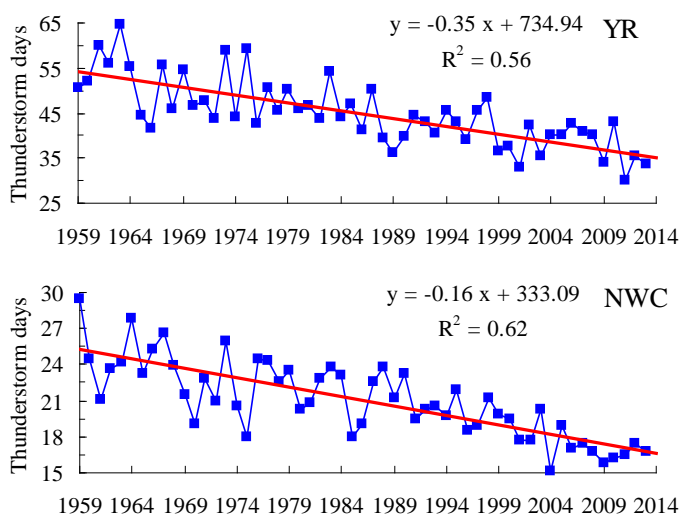
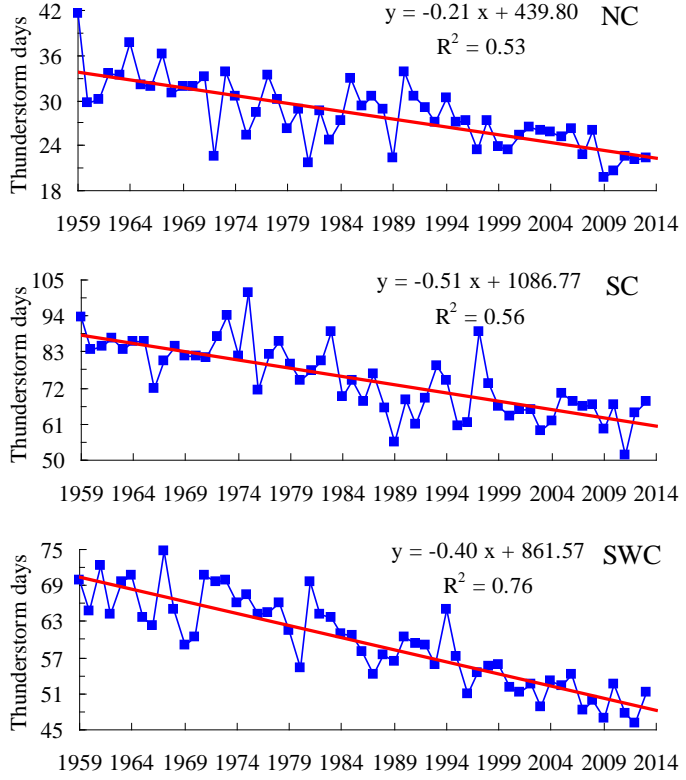

Figure 3. Variations of annual average thunderstorm days in six regions of China during 1959-2013.
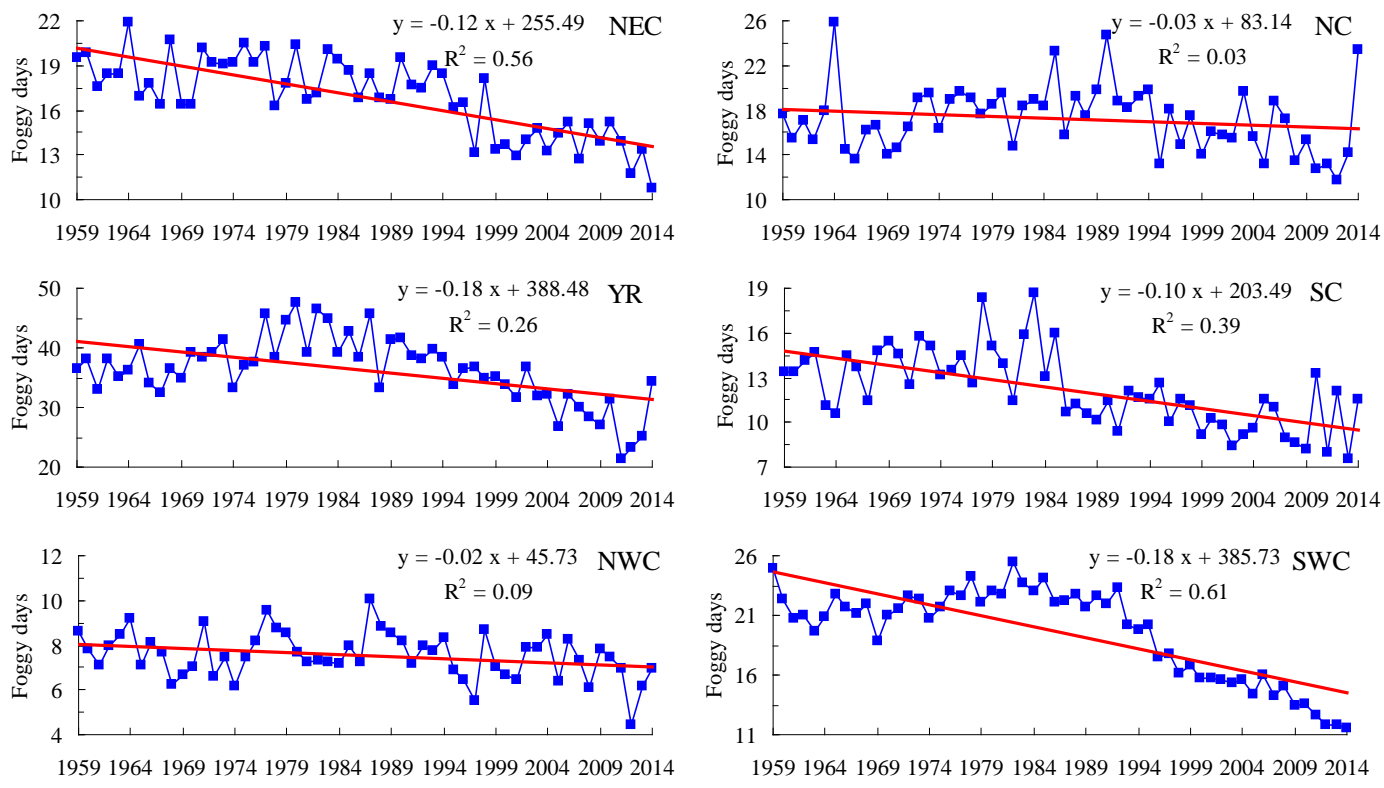

Figure 4. Variations of annual average foggy days in six regions of China during 1959-2014.

in both days and spells of foggy weather were not significant. During 2001-2014, the number of days and spells of foggy weather was the smallest in NEC, NC, YR, NWC and SWC, and in the 1980s, it was the largest in NC, YR, NWC and SWC. In NEC and SC, both the days and the spells of foggy weather were the highest in the 1970s. The maximum days and spells of foggy weather occurred at Mount Emei station in Sichuan, which was 338 days in 1973 and 1983 and 35 times in 2009 respectively.

\subsubsection{Temporal variations in annual hailstorm days and hailstorm spells}

Annual average days and spells of hailstorms decreased in all six regions of China, especially in NEC, NC, NWC and SWC, the decreasing trends in both days and spells of hailstorms were all significant during 1959-2014 (Table 1 and Fig. 5). The occurrence of hailstorm events decreased at rates of $0.3,0.3,0.3$ and 0.7 days per decade, and the occurrence of hailstorm spells decreased at rates of 0.001, 0.002, 0.008 

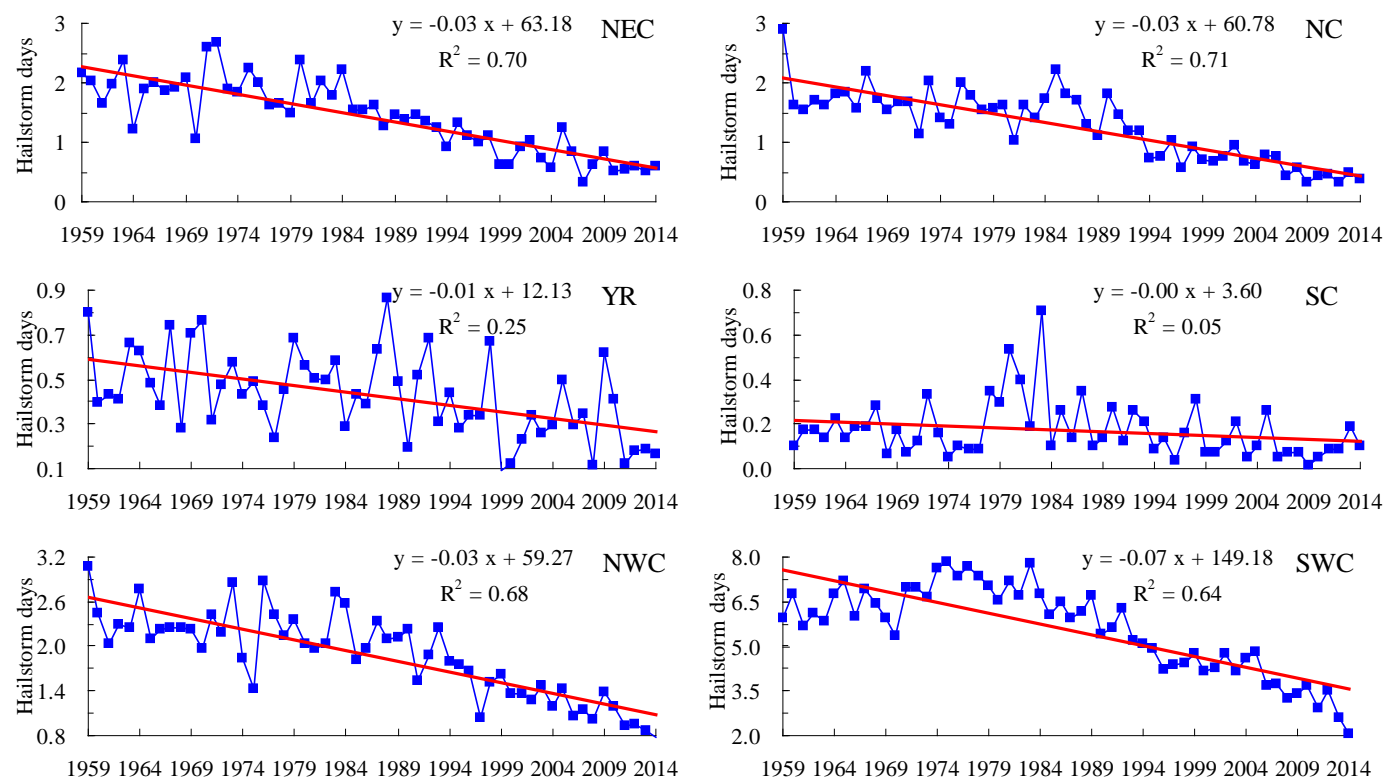

Figure 5. Variations of annual average hailstorm days in six regions of China during 1959-2014.

and 0.043 times per decade in NEC, NC, NWC and SWC respectively. In SC, the decreasing trend in both days and spells of hailstorm was not significant. During 2001-2014, the number of days and spells of hailstorms was the smallest in NC, NWC and SWC, and during 1959-1970, it was the largest in NC and NWC. The maximum days and spells of hailstorms occurred at Nagchu station in Tibet, 53 days and 8 times respectively in 1976.

\subsection{Spatial characteristics of the days of high-impact weather}

\subsubsection{Spatial distribution in average annual number of days of high-impact weather}

During 1959-2014, the average annual number of days of snowfall was more in northeastern and western China, but less in southern China (Fig. 6a). In Heilongjiang, Jilin, eastern Liaoning, Gansu, Qinghai, Tibet, western Sichuan and most parts of Inner Mongolia and Xinjiang, the number of snowfall events was over 25 days per year on average, especially in most parts of Heilongjiang, eastern Jilin, northeastern Inner Mongolia, northern Xinjiang, central and southern Qinghai, northeastern Tibet and northwestern Sichuan, where it was over 50 days per year. In eastern Sichuan, Guangdong, Guangxi, Fujian, Hainan, the southern parts of Zhejiang, Hunan and Guizhou, and most parts of Jiangxi and Yunnan, the number of snowfall events was less than 10 days per year. At Tulogart station in Xinjiang, snowfall was the most frequent, with an annual average of 196 days, and at 42 stations, mainly distributed in Hainan, southern Guangdong, southern Guangxi and southwestern Yunnan, there was no snowfall during 1959-2014.
The average annual number of days of thunderstorms was more in southern and southwestern China, but less in northwestern China, except for a few stations in western Xinjiang (Fig. 6b). In southwestern Zhejiang, Jiangxi, most parts of Hunan and Guizhou, western Sichuan, southern Qinghai, central and eastern Tibet, Yunnan, Guangxi, Guangdong and Hainan, the number of thunderstorm events was over 45 days per year on average, especially in southwestern Fujian, southern Jiangxi, Guangdong, Guangxi, Hainan, Yunnan, southwestern Sichuan and central Tibet, where it was over 60 days per year. In western Inner Mongolia, western Gansu, northwestern Qinghai, eastern and southern Xinjiang, the number of thunderstorm events was less than 20 days per year. At Mengle station in Yunnan, thunderstorms were the most frequent, with an average of 113 days per year.

The average annual number of days of foggy weather was more at some high mountain stations, but less in western China and Inner Mongolia during 1959-2014 (Fig. 6c). At Mount Tai, Huang, Jiuxian and Emei stations, the number of foggy weather events was over 100 days per year on average. In eastern China, central China and some areas of southwestern and northeastern China, including southern Hebei, central and eastern Henan, Shandong, Jiangsu, Anhui, Shanghai, Jiangxi, Zhejiang, Fujian, Hubei, Hunan, southern Shaanxi, eastern Sichuan, Guizhou, southern Yunnan, northern Heilongjiang, eastern Jinli and eastern Liaoning, the number of foggy weather events was over 20 days per year. In Tibet, Qinghai, southern and central Xinjiang, Ningxia, most parts of Gansu and Inner Mongolia, the number of foggy weather events was less than 10 days per year. At Mount Emei station in Sichuan, foggy weather was the most frequent, with an annual average of 312 days, and at 21 stations mainly dis- 

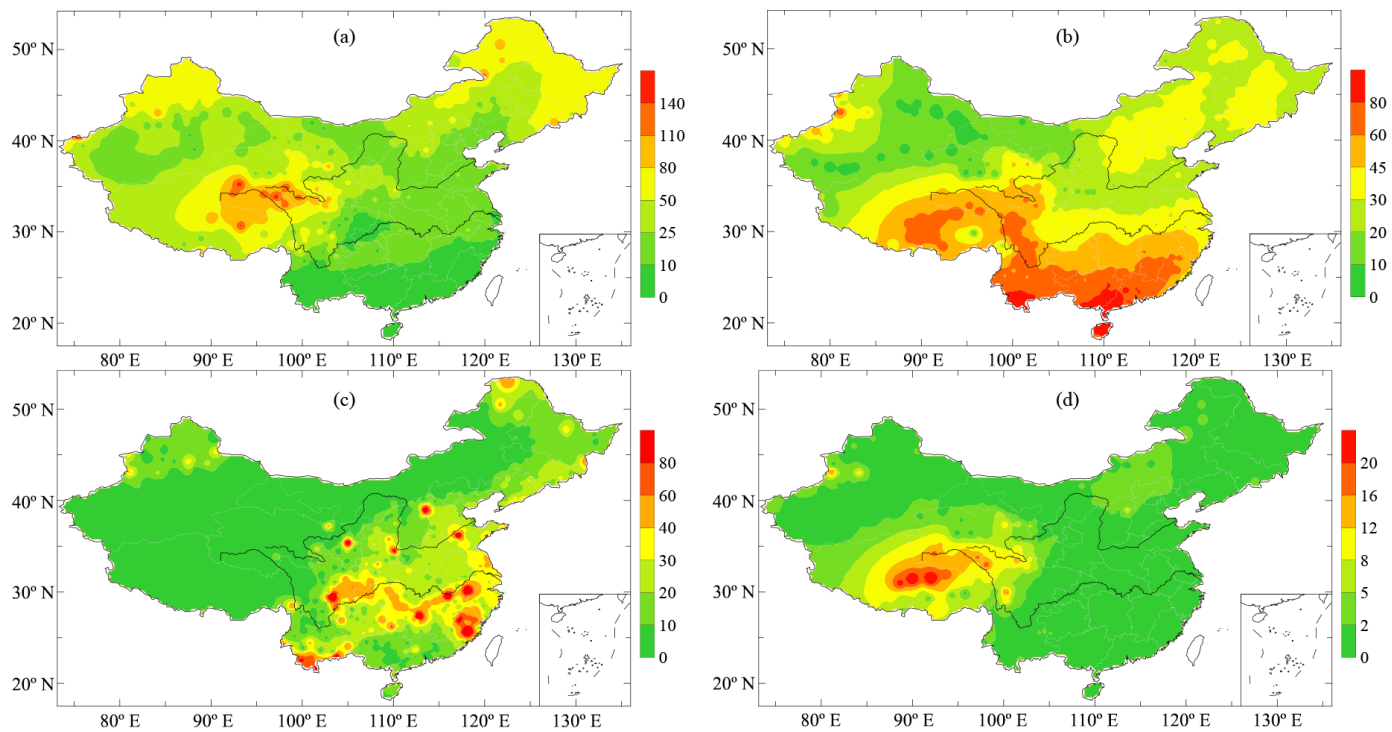

Figure 6. Spatial distribution of annual days of high-impact weather in China during 1959-2014 (unit: days yr ${ }^{-1}$; (a) snowfall days, (b) thunderstorm days, (c) foggy days, (d) hailstorm days).
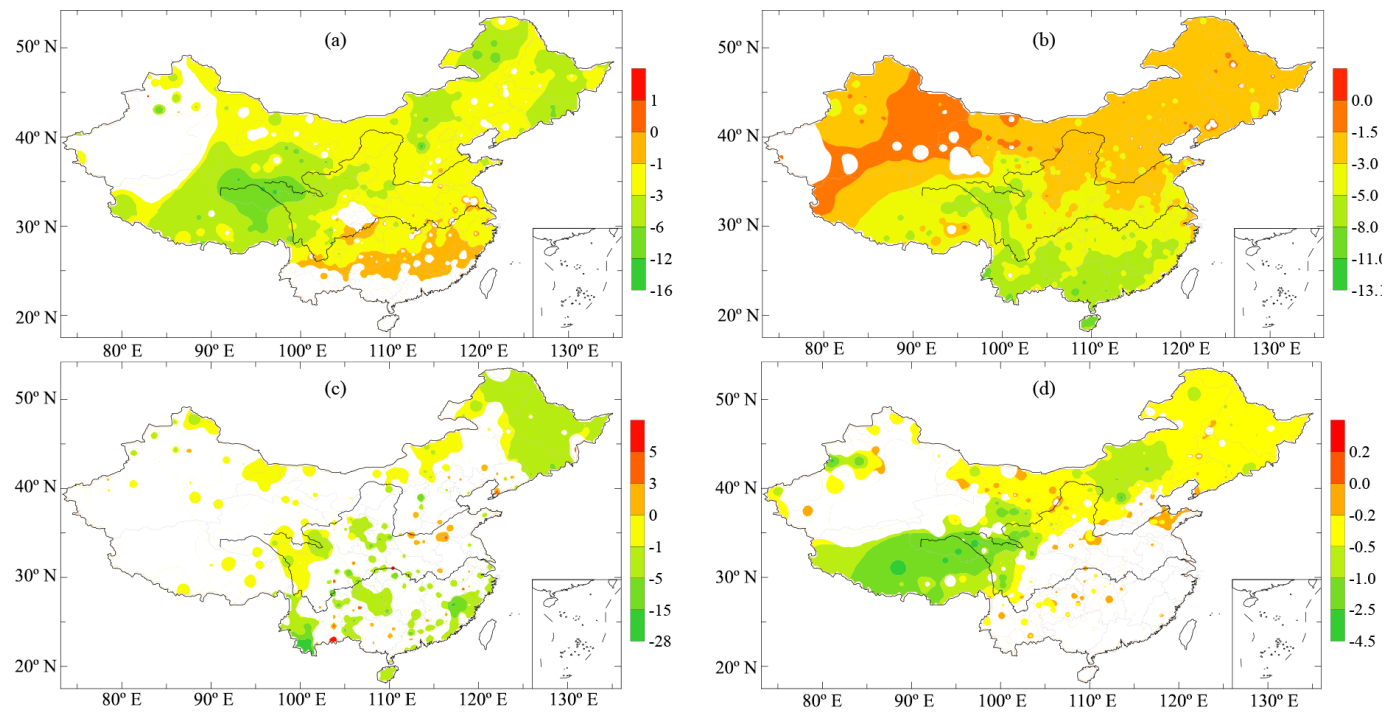

Figure 7. Spatial trend of annual days of high-impact weather in China during 1959-2014 (unit: days decade ${ }^{-1}$; (a) snowfall days, (b) thunderstorm days, (c) foggy days, (d) hailstorm days).

tributed in northern Qinghai, western Sichuan and eastern Tibet, there was no foggy weather during 1959-2014.

During 1959-2014, the average annual number of days of hailstorms was more in southern Qinghai and central Tibet, with an average of over 8 days per year (Fig. 6d). In Qinghai, Tibet, southwestern Gansu, western Sichuan, some small parts of western Xinjiang, central-eastern Inner Mongolia, northern Hebei and northern Shanxi, the number of hailstorm events was over 2 days per year. In other regions, the number of hailstorm events was less than 2 days per year. At Nagchu station in Tibet, hailstorms were the most frequent, with an annual average of 32 days, and at 22 stations mainly dis- tributed in southern Fujian, southern Guangdong, southern Guangxi and Hainan, there were no hailstorms during 19592014.

\subsubsection{Spatial trend in annual days of high-impact weather}

During 1959-2014, snowfall decreased significantly at rates of 1.0-12.0 days per decade in most of China (Fig. 7a), especially in most parts of Qinghai, central and eastern Tibet, western Sichuan, central-eastern Heilongjiang, eastern Jilin, northern Shanxi and some parts of eastern Inner Mongolia, 

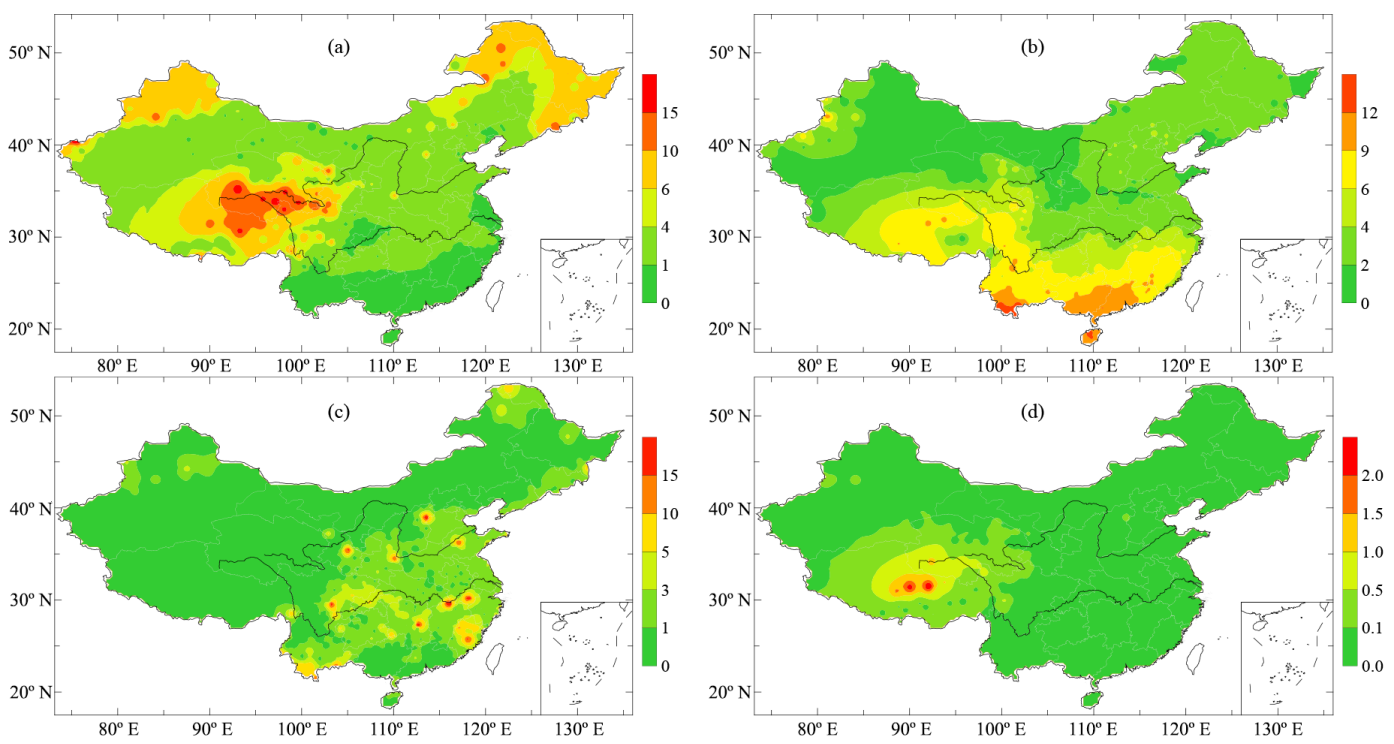

Figure 8. Spatial distribution of annual number of high-impact weather spells with more than 3 consecutive days in China during 1959-2014 (unit: times $\mathrm{yr}^{-1}$; (a) snowfall spells, (b) thunderstorm spells, (c) foggy weather spells, (d) hailstorm spells).

southern Gansu and central Shaanxi, where they decreased at a rate of more than 3.0 days per decade. In Hainan, most parts of Guangxi, Guangdong and Xinjiang, northwestern Tibet, central and southern Yunnan, southern Fujian, eastern Sichuan and some scattered areas of other provinces, the trend of snowfall was not significant. In other regions, snowfall decreased significantly at a rate of $0-1.0$ days per decade.

Thunderstorms showed a decreasing trend in almost the whole of China during 1959-2013 (Fig. 7b). In southwestern Xinjiang and some scattered areas of northwestern Qinghai, northwestern Gansu, eastern Xinjiang, western Inner Mongolia and Heilongjiang, Liaoning and Tibet, the trend of thunderstorms was not significant. In other regions, thunderstorms decreased significantly and the decreasing trend was greater in southern China than in northern China. In northeastern China and northern China, thunderstorms decreased mainly at a rate of 1.5-3.0 days per decade, but in regions south of Shandong, Henan, northern Shaanxi, eastern and northern Gansu, northwestern Qinghai and northwestern Tibet, they decreased mainly at a rate of 3.0-8.0 days per decade.

The trend of foggy weather was not significant in most of China during 1959-2014 (Fig. 7c). In the eastern parts of northeastern China, including Jilin, most of Heilongjiang and some parts of northeastern Inner Mongolia, and Hainan, western Yunnan, northern Fujian, eastern Guizhou, western Sichuan, northwestern Gansu and some scattered areas of other provinces, foggy weather decreased significantly at a rate of 0-15.0 days per decade. In some scattered areas of western Shandong, Henan, Liaoning, Hebei, eastern Yunnan, Guangxi, Guizhou, eastern Sichuan and other provinces, foggy weather increased significantly at a rate of 0-5.0 days per decade, though the areas were very small. In other large regions, the trend of foggy weather was not significant.

During 1959-2014, the occurrence of hailstorms decreased in northeastern China, Inner Mongolia, northern Hebei, northern and central Shanxi, northern Shaanxi, Ningxia, most of Gansu, southern and eastern Qinghai, western Sichuan, most of Tibet and some scattered areas of Xinjiang, with significant rates of $0.2-4.5$ days per decade in most areas (Fig. 7d). In some scattered areas of central Shandong, southern Hebei, southern Shaanxi, western Inner Mongolia, Hunan, Guizhou, Yunnan, Xinjiang and other provinces, the occurrence of hailstorms decreased significantly at a rate of $0-0.2$ days per decade. In other large regions, mainly concentrated in northwestern China, eastern China, central China and southern China, the trend of hailstorms was not significant.

\subsection{Spatial characteristics of the spells of high-impact weather}

\subsubsection{Spatial distribution in average annual number of weather spells}

During 1959-2014, snowfall spells were more frequent in northeastern China, northwestern Xinjiang and QinghaiTibetan Plateau, but less in southern China (Fig. 8a). In northeastern Inner Mongolia, most parts of Heilongjiang and Tibet, eastern Jilin, northwestern Xinjiang, eastern and southern Qinghai, western Sichuan and southwestern Gansu, snowfall spells occurred more than four times per year on average, especially in some parts of southern Qinghai and north-central Tibet, where they occurred more than 10 times per year. In central and southern Jiangsu, the southern 

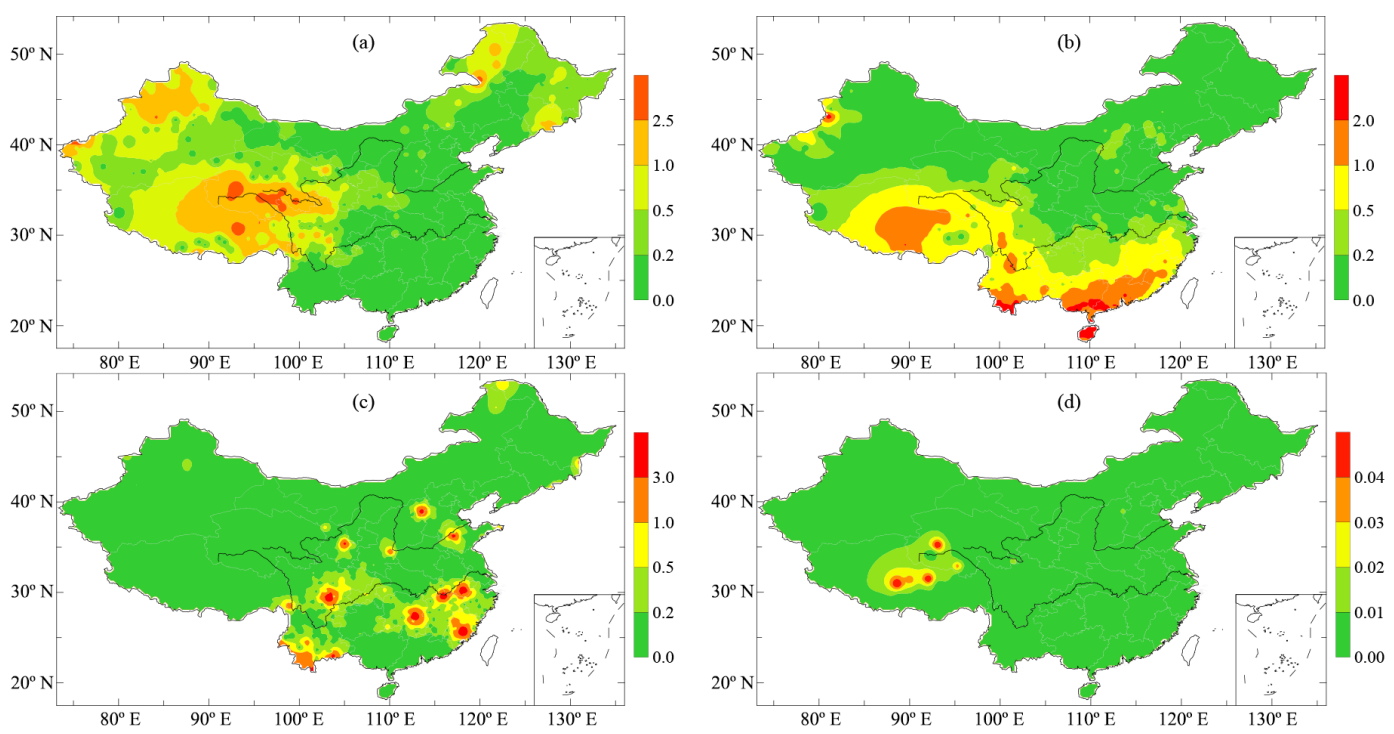

Figure 9. Spatial distribution of annual number of high-impact weather spells with more than 7 consecutive days in China during 1959-2014 (unit: times $\mathrm{yr}^{-1}$; (a) snowfall spells, (b) thunderstorm spells, (c) foggy weather spells, (d) hailstorm spells).

parts of Zhejiang, Hunan and Guizhou, eastern and southern Jiangxi, Fujian, Guangdong, Guangxi, Hainan, most parts of Yunnan and some parts of eastern Sichuan and western Liaoning, snowfall spells occurred less than once a year. At Tulogart station in Xinjiang, snowfall spells were the most frequent, with an average of 25.7 times per year, and at 58 stations mainly distributed in Hainan, southern Guangxi, southern Guangdong and southwestern Yunnan, there were no snowfall spells during 1959-2014.

Thunderstorm spells were more frequent in southern and southwestern China, but less in most areas of northwestern China (Fig. 8b). In most parts of Zhejiang and Hunan, southern Anhui, western Sichuan, southern Qinghai, central and eastern Tibet, Yunnan, Guizhou, Guangxi, Guangdong, Hainan, Jiangxi, Fujian and several stations of western Xinjiang, thunderstorm spells occurred more than four times per year on average, especially in southeastern Guangxi, western and southern Guangdong, southern Yunnan and Hainan, where they occurred more than nine times per year. In western Inner Mongolia, northwestern and eastern Gansu, Ningxia, northwestern Qinghai, eastern and southern Xinjiang, thunderstorm spells occurred less than two times per year. At Mengle station in Yunnan, thunderstorm spells were the most frequent, with an average of 16.0 times per year.

Foggy weather spells were more frequent at some high mountain stations, but less in western China and eastern and central Inner Mongolia during 1959-2014 (Fig. 8c). At Mount Wutai, Tai, Hua, Huang, Jiuxian, Lu, Emei, Heng and Huajialing stations, foggy weather spells occurred over 15 times per year. In eastern China, central China, southern Hebei, eastern and southern Shanxi, central and southern Shaanxi, southeastern Gansu, central and eastern Sichuan, southern Yunnan, Guizhou and some parts of Heilongjiang,
Inner Mongolia, Jilin, Liaoning and Xinjiang, foggy weather spells occurred more than once a year in most areas. In other regions, foggy weather spells occurred less than once a year. At Mount Lu station in Jiangxi, foggy weather spells were the most frequent, with an annual average of 26.9 times, and at 99 stations mainly distributed in Tibet, Qinghai, western Sichuan, Gansu and southeastern Xinjiang, there were no foggy spells during 1959-2014.

Hailstorm spells were more frequent in southwestern Qinghai and north-central Tibet, with an annual average occurrence of over 0.5 times during 1959-2014 (Fig. 8d). In most areas of China, including northeastern China, northern China, eastern China, central China, southern China, and Xinjiang, Gansu, central and eastern Sichuan, Yunnan and Guizhou, there have been no hailstorm spells over the past 56 years. At Nagchu station in Tibet, hailstorm spells were the most frequent, with an average of 2.6 times per year.

\subsubsection{Spatial distribution in average annual number of long weather spells}

Long snowfall spells were more frequent in Qinghai-Tibetan Plateau, Xinjiang, Gansu and northeastern China, but less frequent in southern China, eastern China and northern China during 1959-2014 (Fig. 9a). In northeastern Inner Mongolia, northern Heilongjiang, eastern Jilin, western Xinjiang, most of Tibet, southern Qinghai and western Sichuan, long snowfall spells occurred more than 0.5 times per year on average, especially in some parts of southern Qinghai, northern and eastern Tibet, northwestern Xinjiang and northwestern Sichuan, where they occurred more than once per year. In almost all areas of southern China, eastern China and northern 
China, long snowfall spells occurred less than 0.2 times per year.

Long snowfall spells accounted for a higher proportion of the total snowfall spells in western China. In Xinjiang, Tibet, southern and central Qinghai, eastern and central Sichuan, the southern parts of Gansu and Shaanxi, the western parts of Henan and Hubei, northwestern Guizhou, most parts of Zhejiang and Hunan, northern Fujian, northern and central Jiangxi and some areas of northeastern Inner Mongolia and eastern Jilin, long snowfall spells accounted for over $6 \%$ of the total snowfall spells, especially in western and southern Xinjiang, northern Tibet and southern Qinghai, where they accounted for over $12 \%$ of the total snowfall spells. In other regions of China, long snowfall spells accounted for less than $6 \%$ of the total snowfall spells during 1959-2014.

Long thunderstorm spells were more frequent in southern and southwestern China, but less in most areas of northeastern China, northern China and northwestern China (Fig. 9b). In southwestern Zhejiang, most of Jiangxi, southern Hunan, some parts of southern Anhui, southwestern Guizhou, western Sichuan, southern Qinghai, most of Tibet, Yunnan, Guangxi, Guangdong, Hainan, Fujian and several stations of western Xinjiang, long thunderstorm spells occurred more than 0.5 times per year on average, especially in Hainan, southeastern Guangxi, most of Guangdong, southwestern Yunnan, central Tibet, southwestern Fujian and small parts of southern Jiangxi, southwestern Sichuan and western Xinjiang, where they occurred more than once a year. In northeastern China, most of northern China, Shandong, northern Qinghai, most of Inner Mongolia, Xinjiang and Gansu, Ningxia, Shaanxi, eastern Sichuan, the northern parts of Hubei, Anhui and Jiangsu, long thunderstorm spells occurred less than 0.2 times per year.

Long thunderstorm spells accounted for higher proportion of the total thunderstorm spells in southern China and southwestern China. In northern and central Jiangsu, northern and southern Anhui, eastern Hubei, central and southern $\mathrm{Hu}-$ nan, most of Guizhou, eastern and southern Sichuan, southern Qinghai, most of Tibet, Yunnan, Guangdong, Guangxi, Hainan, Fujian, Jiangxi, most of Zhejiang, and some small areas of Inner Mongolia, Xinjiang and northwestern Shanxi, long thunderstorm spells accounted for over $6 \%$ of the total thunderstorm spells, especially in western and central Fujian, most of Guangdong, Hainan, southeastern Guangxi, southern Yunnan, central Tibet, and some small areas of Sichuan, Guizhou and Xinjiang, where they accounted for over $12 \%$ of the total thunderstorm spells. In other regions of China, long thunderstorm spells accounted for less than $6 \%$ of the total thunderstorm spells during 1959-2013.

Long foggy weather spells were more frequent in southern Yunnan and at some high mountain stations, but less frequent in most other areas of China (Fig. 9c). At Mount Wutai, Tai, Huang, Jiuxian, Lu, Emei, Heng and Huajialing stations and Pingbian and Mengle stations, long foggy weather spells occurred more than four times per year. In most ar- eas of Zhejiang, Jiangxi, Fujian, southern Anhui, eastern $\mathrm{Hu}-$ nan, Chongqing, southwestern Sichuan and southern Yunnan, long foggy weather spells occurred more than 0.2 times per year. Long foggy weather spells accounted for higher proportion of the total foggy weather spells in some high mountain stations and southwestern Yunnan. Long foggy weather spells accounted for over $25 \%$ of the total foggy weather spells at Mount Wutai, Tai, Huang, Jiuxian, Lu, Emei and Huajialing stations and Pingbian and Mengle stations in Yunnan. In northwestern and southeastern Tibet, southwestern Yunnan, Chongqing, eastern Sichuan, central Fujian and some small areas of western Xinjiang, southern Gansu, southern Shaanxi, southern Guizhou, southwestern Hubei, Heilongjiang and northeastern Inner Mongolia, long foggy weather spells accounted for over $6 \%$ of the total foggy weather spells. In other regions of China, long foggy weather spells accounted for less than $6 \%$ of the total foggy weather spells during 1959-2014.

Long hailstorm spells were mainly distributed in eight stations in southwestern Qinghai and north-central Tibet, with an annual average occurrence of more than 0.02 times during 1959-2014 (Fig. 9d). At Wudaoliang station in Qinghai, and Nagchu and Xainza stations in Tibet, long hailstorm spells were the most frequent, all with an average occurrence of 0.05 times per year. The number of long hailstorm spells accounted for $1.6-7.5 \%$ of the total hailstorm spells at eight stations with over 7 consecutive hailstorm days.

\subsubsection{Spatial trend in annual number of weather spells}

During 1959-2014, snowfall spells decreased at a rate of 0.21.3 times per decade in eastern and southern Qinghai, eastern Tibet, western and southern Sichuan, southern Gansu, southern Ningxia, most of Shaanxi, northern and southwestern Shanxi, northern and western Hebei, western Henan, northwestern Hubei, northeastern Shandong, most of Heilongjiang, eastern Jilin and some parts of eastern and central Inner Mongolia, and the trend was statistically significant (Fig. 10a). In southeastern Shandong, northeastern Jiangsu, southern Zhejiang and some scattered areas of Jiangxi, Hunan and Guangxi, snowfall spells decreased significantly at a rate of less than 0.2 times per decade. In other regions, the trend of snowfall spells was not significant.

Thunderstorm spells decreased significantly in most of China during 1959-2013 (Fig. 10b), and the decreasing trend was greater in southern China than in northern China. In eastern and southern Xinjiang, northwestern Qinghai, northwestern Tibet, western Gansu and western Inner Mongolia, the trend of thunderstorm spells was not significant. In northeastern China, central Inner Mongolia, northeastern Xinjiang, western Shaanxi, eastern Gansu, northern Shanxi and some areas of western Tibet, Henan and Hebei, thunderstorm spells decreased significantly at a rate of $0.2-0.4$ times per decade. In Yunnan, Guangxi, Hainan, western Sichuan and southeastern Qinghai, western Fujian and in most parts of Jiangxi, Hu- 

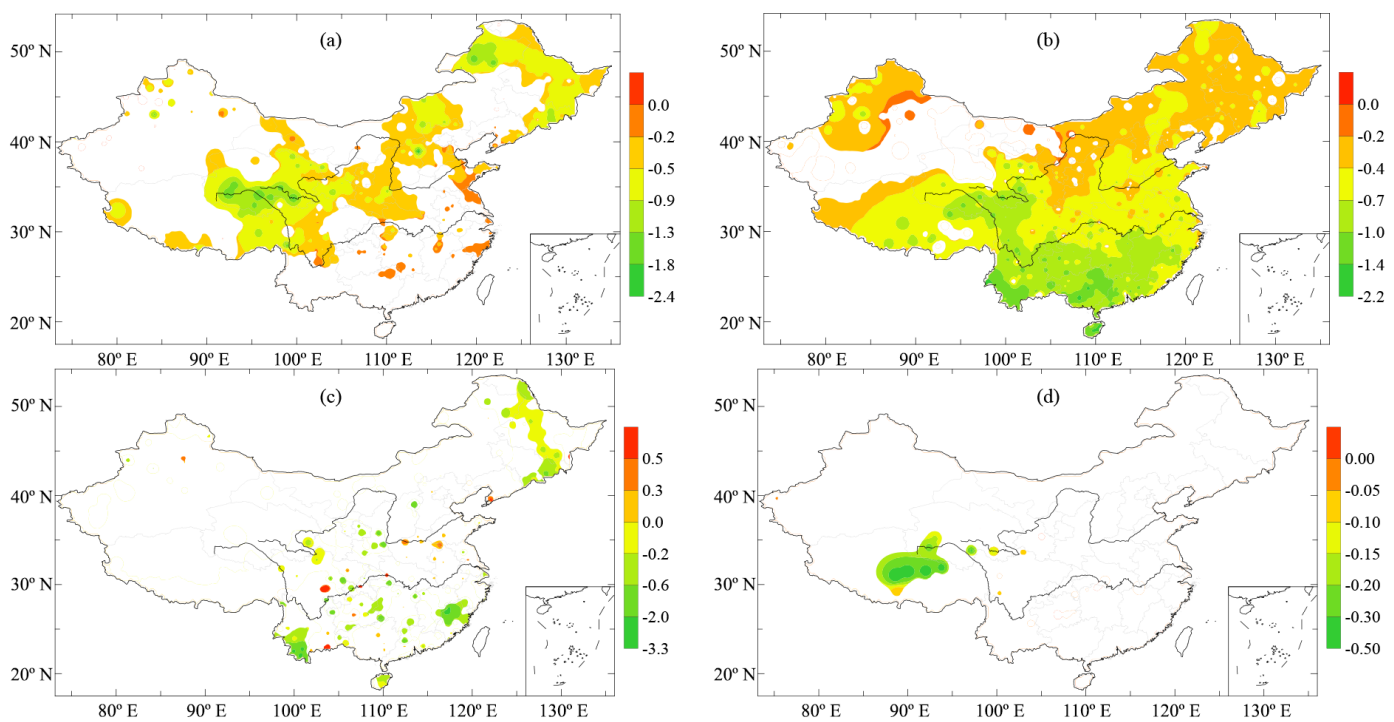

Figure 10. Spatial trend of annual number of high-impact weather spells in China during 1959-2014 (unit: times decade ${ }^{-1}$; (a) snowfall spells, (b) thunderstorm spells, (c) foggy weather spells, (d) hailstorm spells).

nan, Guizhou and Guangdong, they decreased significantly at a rate of 0.7-1.4 times per decade. In other regions, thunderstorm spells decreased significantly at a rate of $0.4-0.7$ times per decade.

The trend of foggy weather spells was not significant in the great majority of China (Fig. 10c). In eastern Jilin, northern Fujian, eastern Hainan, southwestern Yunnan, and some scattered areas of Heilongjiang, eastern Inner Mongolia, Shaanxi, Sichuan, Guizhou, Hunan, Jiangxi and Guangdong, foggy weather spells decreased with rates of $0-2.0$ times per decade, and the trend was significant. In other regions, the trend of foggy weather spells was not significant.

Since the annual number of hailstorm spells was less in the great majority of China, the trend of hailstorm spells was not significant in the whole of China except for north-central Tibet and southwestern Qinghai, where the occurrence of hailstorm spells decreased significantly at a rate of $0.05-0.5$ times per decade during 1959-2014 (Fig. 10d).

\section{Discussion}

High-impact weather (HIW) refers to the weather events or climatic phenomena or their abnormities that may cause serious disasters and have an impact on social economies, the natural environment and human activities (Shi et al., 2015). HIW events can disrupt transportation and communication, damage homes and property, claim the lives of people, and etc. In China, HIW events are frequent due to the various climate regimes, complex topography and the strong influence of the East Asian monsoon system (Fu et al., 2013). Every year many Chinese people suffer as a result of typhoons, storms, floods, hail, drought, wind and other meteorologi- cal disasters. Meteorological disasters are estimated to have caused an economic loss of 3 to $6 \%$ of GDP each year since 1990 (Jiang et al., 2012). More accurate information on HIW is thus a critical need of society (Done et al., 2015). The temporal patterns and spatial trends of catastrophic floods, droughts, storms, and heatwaves or cold spells have been receiving much more attention in recent years as a result of the tremendous loss caused by meteorological disasters ( $\mathrm{Wu}$ et al., 2014). A deep understanding of HIW is also essential for enhancing forecast capability, strengthening risk management and planning adaptation strategies.

Climate change will strongly affect the frequency of snowfall. A significant decreasing trend in the frequency of snowfall days was observed between 1959 and 2014 in most of China (Fig. 7a), and this trend was also found by other studies from different parts of the China. For example, Wang et al. (2011) analysed the changing characteristics of snowfall days in Liaoning province during 1961-2007, and the results showed that there was a significant decreasing trend of snowfall days ( 1.6 days per decade). The remarkable reduction of snowfall days was mainly due to the reduction of days of light snow and trace snow, especially the trace snow. Zhu et al. (2014) analysed the spatiotemporal variation patterns of snowfall days in Qinghai province during 1962 to 2012 and the results also showed a decreasing trend of snowfall days at a rate of 1-3 days per decade. The climate characteristics of the frequency of snowfall days in Ningxia during the period of 1961 to 2010 were also analysed, and results showed that the total number of snowfall days had decreased, with a reduction in light snow, heavy snow and snowstorms days, and the opposite trend for moderate snow days (Ding et al., 2012). 
Many simulations show that with the increase of global mean temperature and total precipitation, snowfall will be reduced, especially in the low to midlatitude regions (Kapnick and Delworth, 2013; O'Gorman, 2014; Lute et al., 2015). Projections with 18 coupled global climate models from the Coupled Model Intercomparison Project 5 (CMIP5) indicate that snowfall will decrease across much of the Northern Hemisphere while increase at higher latitudes during the twenty-first century under the RCP4.5 scenario (Krasting et al., 2013). In almost all northern Europe, a decrease in the winter total snowfall in twenty-first century was also suggested by 12 regional models under the SRES A1B scenario (Räisänen, 2015). The decreasing trend of snowfall across most areas of Northern Hemisphere may be due to the observed decrease of snow/rain ratio caused by the increase of air temperature (Marty and Blanchet, 2012; Krasting et al., 2013). Knowles et al. (2006) also found that the ratio of snowfall water equivalent (SFE) to total precipitation $(P)$ became smaller in winter in the western United States during 1949-2004. During the mid-twenty-first century, annual SFE and snowfall days would decline for all stations in the western United States (Lute et al., 2015). Piazza et al. (2014) found that temperature change had an important influence on the spread of snowfall at the time of beginning and ending of the cold season from November to March over the French Alps during the 21st century, but in January and February, no link was found between temperature and snowfall.

For the changes in snowfall extremes, simulations with climate models indicate that over many Northern Hemisphere land regions, the intensities of daily snowfall extremes will have smaller fractional changes than mean snowfall by the late twenty-first century, and the initial temperature for snowfall extremes and mean snowfall to decrease with warming is -9 and $-14^{\circ} \mathrm{C}$ respectively (O'Gorman, 2014). Lute et al. (2015) also found that the magnitude of snowfall extremes have a relative increase compared to annual SFE, and snowfall extremes will account for a larger fraction of annual SFE in both warmer and colder sites in the western United States during the mid-twenty-first century. Vries et al. (2014) showed that seasonal snowfall extremes will decrease with comparable or even larger trends than the number of Hellmann days (snowfall days where the mean temperature is below freezing) and the mean Hellmann-day snowfall over large parts of western and central Europe, with a local intensity reduction of $-30 \%$ per degree warming, which is in sharp contrast to the increase of winter precipitation projected in most climate scenarios.

With global warming, it is very important to consider the potential effects of climate change on thunderstorms (Brooks, 2013). During 1959-2013, a significant decreasing trend was detected in the frequency of thunderstorm days in almost all of China, and the occurrence of thunderstorm days decreased more in southern China than in northern China (Fig. 7b). Chen et al. (2009) examined the occurrence of thunderstorm days at 743 stations in China based on the ob- servations from 1951 to 2005 , and the results showed that except a slight increase in the Qinghai-Tibet Plateau, the thunderstorm days had a decreasing tendency in the other areas of China. Yu et al. (2012) analysed the frequency variation of thunderstorms in eastern China from 1971 to 2000 and the results indicated that the frequency of thunderstorms had a decreasing trend, especially to the south of the Yangtze River, where the frequency of thunderstorms showed a more significant decreasing trend.

Thunderstorm is frequently accompanied by gale, rainstorm and sometimes hail, and it can cause many fatalities or serious injuries each year despite advance warnings. It is generally assumed that rising temperature associated with global warming will lead to the increase of thunderstorm intensity and precipitation extremes. Ashley et al. (2012) also demonstrated a positive urban amplification of thunderstorm frequency and intensity for major cities in the southeastern United States. However, research on the relationship between thunderstorms and the global climate has been more limited. Marsh et al. (2009) indicated that in Europe, climate models were able to produce reasonable distributions of severe thunderstorms, though the interpretation of the magnitudes is unconfident. Global models have the horizontal resolution of tens or larger kilometres, so it is also difficult to deal with the thunderstorms on a small horizontal scale (Brooks, 2013). Allen and Karoly (2014) suggested that though El Niño-Southern Oscillation (ENSO) had a great influence on the spatial pattern of severe thunderstorm environments over Australia, the link between ENSO and the occurrence of severe thunderstorms is more uncertain.

Fog has been regarded as a dangerous weather phenomenon that may cause car accidents and bad impacts on power supply, urban air quality and human health. Therefore, studies on the changes in frequency and intensity of fog caused by climate change are of high importance (Avotniece et al., 2015). During 1959-2014, a significant decreasing trend was detected in the frequency of foggy days in most regions of China, and foggy days increased firstly and then decreased continuously in some regions (Fig. 4). Shi et al. (2010) studied the change characteristics and causes of foggy days in eastern China, and results also indicated that the number of foggy days increased initially and then decreased during 1961-2007. Ding and Liu (2014) also found that foggy days in China had experienced two stages of change from 1961 to 2011, with an increasing number of foggy days before 1980 and a decreasing occurrence after 1990. The significant decrease of foggy days had also been observed in the Gansu and Shanxi provinces of China (Wang et al., 2005). Spatially, the change trend of foggy days was not significant in most of China (Fig. 7c).

Akimoto and Kusaka (2015) studied the climatological characteristics of fog in Japan and the results indicated that the numbers of foggy days decreased at many of the observation sites during a 40-year period from 1966 to 2005. The decreasing trend of fog frequency was also found in Latvia 
across a 52-year period (Avotniece et al., 2015). Dense fog with visibility less than $400 \mathrm{~m}$ seems to be reduced in many parts of the world (LaDochy and Witiw, 2012). An airport visibility assessment of fog frequency in the Central Valley of California revealed that fog occurrence had decreased substantially, and overall dense fogs with visibility of less than $1 / 4$ mile had decreased by $\sim 50 \%$ since the 1980 s (Herckes et al., 2015). Temperature increase or vapour reduction due to urbanization, global warming followed by synoptic-scale climate change, and variation in aerosol concentration and air quality may affect the formation of fog (Shi et al., 2010; Akimoto and Kusaka, 2015; Avotniece et al., 2015). The decrease of fog in urban areas has also been reported in some cities in the United States, where it is said to reflect the reduction of particulates, the intensification of urban heat island and Pacific sea surface temperature, along with large-scale interaction of the atmosphere and the ocean (LaDochy and Witiw, 2012).

In midlatitude countries, hailstorms have been a serious meteorological disaster because of their local-scale development, large spatial and temporal variability, short time span and a lack of appropriate monitoring and forecasting systems (García-Ortega et al., 2014; Baldi et al., 2014). Nowadays, hailstorms are not captured reliably and comprehensively over long periods by current observation systems (Mohr and Kunz, 2013). However, in China, there are many stations with daily observation of the occurrence or non-occurrence of hailstorms, and recordation of the size of the largest hailstone (Brooks, 2013). A significant decreasing trend in the frequency of hailstorm days was detected in most regions of China during 1959-2014 (Fig. 5). Xie et al. (2008) analysed the variation and trend in hailstorm frequency during 19602005 in China and the results showed no trend in the mean annual hailstorm days from 1960 to early 1980s, but a significant decreasing trend afterwards. The decrease in surface hailstorms is primarily due to the increase in the height of the environmental melting level resulting from climate warming, as the warmer atmosphere enhances the melting of frozen precipitation (Mahoney et al., 2012).

Hailstorm damage is usually proportional to the hailstone size and density (number of hailstones per unit area), and to the strength of the winds associated with the storms (Baldi et al., 2014). The impact of climate warming on the frequency and intensity of hailstorms is largely unknown (Mahoney et al., 2012). In the Greater Metropolitan Severe Thunderstorm Warning Area of New South Wales, a significant decreasing trend in the frequency and associated magnitude (size) of hail events was identified during 1989-2013 (Rasuly et al., 2015). In China, Xie et al. (2010) reported that the long-term trend of hailstorm size in four regions of China was statistically insignificant for the period of 1980-2005, but Wu et al. (2015) found an increasing trend in the frequency and intensity of hailstorms in Xinjiang, Northwest China, during the period from 1949 to 2012. In the central-eastern Italian Alps, Eccel et al. (2012) found that the size of hailstorms had increased, though the frequency or cumulative hit surface showed no significant change over a number of years. From hail pad data over France between 1989 and 2009, Berthet et al. (2011) also found that the frequency of hailstorms did not change significantly during 1989-2009, while the intensity increased by $70 \%$ during April and May. Dessens et al. (2015) found that with the increase of the melting level height, there was a decrease in the number of small hailstones $(5$ to $7 \mathrm{~mm}$ diameter) and an increase in the number of larger hailstones, particularly in the 11 to $21 \mathrm{~mm}$ ranges, and in southwestern France, the hail intensity would increase between 2000 and 2040 with global warming.

\section{Conclusions}

The spatial and temporal characteristics of four types of high-impact weather (HIW) were analysed and results show that during 1959-2014, snowfall and thunderstorm days had significant decreasing trends in all regions and foggy and hailstorm days decreased significantly in almost all regions of China. For the weather spells, snowfall spells decreased significantly in almost all regions, thunderstorm spells decreased significantly in all regions, and foggy and hailstorm spells decreased significantly in most regions of China.

Spatially, there were more snowfall days and snowfall spells in northeastern and western China, but fewer in southern China. The number of thunderstorm days and thunderstorm spells was larger in southern and southwestern China, but smaller in northwestern China. There were more foggy days and foggy weather in some high mountain stations, eastern China and central China, but fewer in western China and Inner Mongolia. Hailstorm days and hailstorm spells were mainly concentrated in the Qinghai-Tibet Plateau.

Over the past few decades, snowfall days, thunderstorm days and thunderstorm spells have decreased in most parts of China, and the decreasing trend of thunderstorms was more evident in southern China than in northern China. The number of hailstorm days decreased in northeastern China, most parts of northern China and Tibet, southern Qinghai and western Sichuan. The spatial trend of foggy days, foggy weather spells, snowfall spells and hailstorm spells was not significant in most parts of China.

Climate change can affect both the frequency and the intensity of weather events. The decreasing trends in the frequency of HIW events in China are mainly consistent with other existing results, but the trends in the intensity of HIW are associated with the specific research areas and have a great deal of uncertainty globally. With global warming, some types of HIW, particularly thunderstorms and hailstorms, are likely to increase in their intensities, so more mitigation and adaptation strategies for such HIW are still essential for local government and the public in China. 
Acknowledgements. The present research was supported by the National Natural Science Foundation of China (no. 41571044 and 41001283) and China Clean Development Mechanism (CDM) Fund Project (no. 2012043). We thank Haizhen Mu and Zhongping Shen, Shanghai Climate Center, Shanghai Meteorological Bureau, China, for their contributions.

Edited by: Ricardo Trigo

Reviewed by: two anonymous referees

\section{References}

Akimoto, Y. and Kusaka, H.: A climatological study of fog in Japan based on event data, Atmos. Res., 151, 200-211, 2015.

Allen, J. T. and Karoly, D. J.: A climatology of Australian severe thunderstorm environments 1979-2011: inter-annual variability and ENSO influence, Int. J. Climatol., 34, 81-97, 2014.

Ashley, W. S., Bentley, M. L., and Stallins, J. A.: Urban-induced thunderstorm modification in the Southeast United States, Clim. Change, 113, 481-498, 2012.

Avotniece, Z., Klavins, M., and Lizuma, L.: Fog climatology in Latvia, Theor. Appl. Climatol., 22, 97-109, 2015.

Baldi, M., Ciardini, V., Dalu, J. D., Filippis, T. D., Maracchi, G., and Dalu, G.: Hail occurrence in Italy: towards a national database and climatology, Atmos. Res., 138, 268-277, 2014.

Berthet, C., Dessens, J., and Sanchez, J. L.: Regional and yearly variations of hail frequency and intensity in France, Atmos. Res., 100, 391-400, 2011.

Brooks, H. E.: Severe thunderstorms and climate change, Atmos. Res., 123, 129-138, 2013.

Chen, S., Zhu, W., and Zhou, B.: Climate characteristic and variation tendency of thunderstorm in China, Trans. Atmos. Sci., 32, 703-710, 2009.

China Meteorological Administration: Standard of the surface observation about meteorology, China Meteorological Press, Beijing, 151 pp., 2003.

de Lima, M. I. P., Santo, F. E., Ramos, A. M., and de Lima, J. L. M. P.: Recent changes in daily precipitation and surface air temperature extremes in mainland Portugal, in the period 1941-2007, Atmos. Res., 127, 195-209, 2013.

Dessens, J., Berthet, C., and Sanchez J. L.: Change in hailstone size distributions with an increase in the melting level height, Atmos. Res., 158-159, 245-253, 2015.

de Vyver, H. V.: Evolution of extreme temperatures in Belgium since the 1950s, Theor. Appl. Climatol., 107, 113-129, 2012.

Ding, Y. H. and Liu, Y. J.: Analysis of long-term variations of fog and haze in China in recent 50 years and their relations with atmospheric humidity, Science China (Earth Sciences), 57, 36-46, 2014.

Ding, Y., Feng, J., Ma, S., and Zheng, G.: Climate characteristics of snowfall day numbers in Ningxia and structure of atmospheric circulation, Meteorol. Mon., 38, 1523-1531, 2012.

Done, J., Holland, G., Bruyère, C., Leung, L. Y. R., and SuzukiParker, A.: Modeling high-impact weather and climate: lessons from a tropical cyclone perspective, Clim. Change, 129, 381395, 2015.

Eccel, E., Cau, P., Riemann-Campe, K., and Biasioli, F.: Quantitative hail monitoring in an alpine area: 35 year climatology and links with atmospheric variables, Int. J. Climatol., 32, 503-517, 2012.

Fu, G., Yu, J., Yu, X., Ouyang, R., Zhang, Y., Wang, P., Liu, W., and Min, L.: Temporal variation of extreme rainfall events in China, 1961-2009, J. Hydrol., 487, 48-59, 2013.

García-Ortega, E., Hermida, L., Hierro, R., Merino, A., Gascón, E., Fernández-González, S., Sánchez, J. L., and López, L.: Anomalies, trends and variability in atmospheric fields related to hailstorms in north-eastern Spain, Int. J. Climatol., 34, 3251-3263, 2014.

Glickman, T. S.: Glossary of Meteorology (2nd Edition), American Meteorological Society, Boston, 850 pp., 2000.

Herckes, P., Marcotte, A. R., Wang, Y., Collett Jr, J. L.: Fog composition in the Central Valley of California over three decades, Atmos. Res., 151, 20-30, 2015.

IPCC: Climate Change 2013: The Physical Science Basis, in: Contribution of Working Group I to the Fifth Assessment Report of the Intergovernmental Panel on Climate Change, edited by: Stocker, T. F., Qin, D., Plattner, G.-K., Tignor, M., Allen, S. K., Boschung, J., Nauels, A., Xia, Y., Bex, V., and Midgley, P. M., Cambridge University Press, Cambridge, UK and New York, NY, USA, 1535 pp., doi:10.1017/CBO9781107415324, 2013.

Jiang, Z., Song, J., Li, L., Chen, W., Wang, Z., and Wang, J.: Extreme climate events in China: IPCC-AR4 model evaluation and projection, Clim. Change, 110, 385-401, 2012.

Kapnick, S. B. and Delworth, T. L.: Controls of global snow under a changed climate. J. Climate, 26, 5537-5562, 2013.

Knowles, N., Dettinger, M. D., and Cayan, D. R.: Trends in snowfall versus rainfall in the western United States, J. Climate, 19, 45454559, 2006.

Krasting, J. P., Broccoli, A. J., Dixon, K. W., and Lanzante, J. R.: Future changes in northern hemisphere snowfall, J. Climate, 26, 7813-7828, 2013.

Kruger, A. C. and Sekele, S. S.: Trends in extreme temperature indices in South Africa: 1962-2009, Int. J. Climatol., 33, 661-676, 2013.

LaDochy, S. and Witiw, M.: The continued reduction in dense fog in the southern California region: possible causes, Pure Appl. Geophys., 169, 1157-1163, 2012,

Li, J., Swinbank, R., Ding, R., and Duan, W.: Dynamics and predictability of high-impact weather and climate events, B. Am. Meteorol. Soc., 94, ES179-ES182, 2013.

Lute, A. C., Abatzoglou, J. T., and Hegewisch, K. C.: Projected changes in snowfall extremes and interannual variability of snowfall in the western United States, Water Resour. Res., 51, 960-972, 2015.

Mahoney, K., Alexander, M. A., Thompson, G., Barsugli, J. J., and Scott, J. D.: Changes in hail and flood risk in high-resolution simulations over Colorado's mountains, Nature Clim. Change, 2, 125-131, 2012.

Marsh, P. T., Brooks, H. E., and Karoly, D. J.: Preliminary investigation into the severe thunderstorm environment of Europe simulated by the Community Climate System Model 3, Atmos. Res., 93, 607-618, 2009.

Marty, C. and Blanchet, J.: Long-term changes in annual maximum snow depth and snowfall in Switzerland based on extreme value statistics, Clim. Change, 111, 705-721, 2012. 
Mohr, S. and Kunz, M.: Recent trends and variabilities of convective parameters relevant for hail events in Germany and Europe, Atmos. Res., 123, 211-228, 2013.

O'Gorman, P. A.: Contrasting responses of mean and extreme snowfall to climate change, Nature, 512, 416-418, doi:10.1038/nature13625, 2014.

Piazza, M., Boé, J., Terray, L., Pagé, C., Sanchez-Gomez, E., and Déqué, M.: Projected 21st century snowfall changes over the French Alps and related uncertainties, Clim. Change, 122, 583594, 2014

Räisänen, J.: Twenty-first century changes in snowfall climate in Northern Europe in ENSEMBLES regional climate models, Clim. Dynam., 1-15, 2015.

Rasuly, A. A., Cheung, K. K. W., and McBurney, B.: Hail events across the Greater Metropolitan Severe Thunderstorm Warning Area, Nat. Hazards Earth Syst. Sci., 15, 973-984, doi:10.5194/nhess-15-973-2015, 2015.

Shi, J. and Cui, L.: Characteristics of high impact weathers and meteorological disaster in Shanghai, China, Nat. Hazards, 60, 951969,2012

Shi, J., Cui, L., He, Q., and Sun, L.: The changes and causes of fog and haze days in eastern China, Acta Geogr. Sin., 65, 533-542, 2010.

Shi, J., Chen, B., Mu, H., and Liang, P.: Characteristics and causes of high-impact weathers in the Yangtze River Delta, Plateau Meteorol., 34, 173-182, 2015.

Sills, D. M.: On the MSC forecasters forums and the future role of the human forecastser, B. Am. Meteorol. Soc., 90, 619-627, 2009.

Sun, Y., Zhang, X., Zwiers, F. W., Song, L, Wan, H., Hu, T., Yin, H., and Ren, G.: Rapid increase in the risk of extreme summer heat in Eastern China, Nat. Clim. Change, 4, 1082-1085, 2014.

Vries, H. D., Lenderink, G., and Meijgaard, E. V.: Future snowfall in western and central Europe projected with a high-resolution regional climate model ensemble, Geophys. Res. Lett., 41, 42944299, 2014.
Wang, L., Chen, S., and Dong, A.: The distribution and seasonal variations of fog in China, Acta Geogr. Sin., 60, 689-697, 2005.

Wang, S., Zhang, M., Wang, B., Sun, M., and Li, X.: Recent changes in daily extremes of temperature and precipitation over the western Tibetan Plateau, 1973-2011, Quatern. Int., 313-314, 110 $117,2013$.

Wang, Y., Zhao, C., Yan, X., and Li, D.: Changing characteristics of snowfall and snowfall days in Liaoning Province during 19612007, J. Glaciol. Geocryol., 33, 729-737, 2011.

WMO: The Global Climate 2001-2010: a decade of climate extremes, WMO-no. 1103, World Meteorological Organization, Geneva, Switzerland, 110 pp., 2013.

Wu, J., Fu, Y., Zhang, J., and Li, N.: Meteorological disaster trend analysis in China: 1949-2013, Nat. Resour. J., 29, 1520-1530, 2014.

Wu, M., Chen, Y., and Xu, C.: Assessment of meteorological disasters based on information diffusion theory in Xinjiang, Northwest China, J. Geogr. S., 25, 69-84, 2015.

Xie, B., Zhang, Q., and Wang, Y.: Trends in hail in China during 1960-2005, Geophys. Res. Lett., 35, L13801, doi:10.1029/2008GL034067, 2008.

Xie, B., Zhang, Q., and Wang, Y.: Observed characteristics of hail size in four regions in China during 1980-2005, J. Climate, 23, 4973-4982, 2010.

Xu, X., Du, Y., Tang, J., and Wang, Y.: Variations of temperature and precipitation extremes in recent two decades over China, Atmos. Res., 101, 143-154, 2011.

Yu, R., Zhang, X., Li, G., and Gao, Q.: Analysis of frequency variation of thunderstorm, hail and gale in eastern China from 1971 to 2000, Meteorol. Mon., 38, 1207-1216, 2012.

Zhu, X., Zhang, M., Wang, S., Li, X., Dong, L., and Ren, Z.: Spatiotemporal variation patterns of the beginning and ending dates of snowfall, and snowfall days in Qinghai Province during 1962 to 2012, Chinese, J. Ecol., 33, 761-770, 2014. 